There was an association between hyperlactataemia and the presence of clinical shock in patients studied before transfusion. This suggests that the lactic acid has resulted from tissue hypoxia and consequent anaerobic glycolysis. It may, however, be more directly related to high levels of circulating catecholamines, as has been suggested in experimentally induced haemorrhagic shock (Halmagyi et al., 1967). Arterial hypoxaemia cannot have been an important factor in the present study as the lactate concentration tended to be higher in the patients with a normal arterial oxygen tension. Moreover, the mild degree of hypoxaemia in the other patients (62$80 \mathrm{~mm} \mathrm{Hg}$ ) would not, on the basis of experimental work in animals, be expected to cause lactic acidosis, even in the presence of hypocapnia (Takano, 1968).

The results in the present study suggest that blood transfusion itself can cause a rise in blood lactate concentration. This is in accordance with experiments on animals with haemorrhagic shock, where transfusion with bank blood has caused a fall in blood pH (Nahas et al., 1961). An explanation for these observations is provided by the fact that red blood cells in stored bank blood, with added acid-citrate-dextrose (A.C.D.), metabolize the dextrose anaerobically to lactic acid (Gullbring and Ström, 1956; Nahas et al., 1961). It has been found that the lactate concentration exceeds $100 \mathrm{mg} / 100 \mathrm{ml}$ after 10 days' storage (Gullbring and Ström, 1956), and that the $\mathrm{pH}$ falls to 6.2 after three weeks' storage (Nahas et al., 1961). These observations may have therapeutic implications, since acidosis has been implicated (Gain, 1962) as one of the factors contributing to the high incidence of cardiac arrest following massive blood transfusion (Howland et al., 1956; Le Veen et al., 1960; Boyan and Howland, 1963). Infusion of alkali has been shown to decrease the mortality rate following rapid transfusion in the experimental animal (Nahas et al., 1961) and in patients undergoing major surgery (Howland and Schweizer, 1965).

The results in the present investigation suggest that monitoring of acid-base status is advisable in patients with acute gastrointestinal bleeding who are clinically shocked, especially if rapid blood transfusion is contemplated. It is probably unnecessary in patients who are not clinically shocked. A metabolic acidosis is unlikely to be rapidly corrected by blood transfusion alone, but can be corrected with intravenous sodium bicarbonate solution.

We would like to thank Sir Francis Avery Jones and Dr. T. D. Kellock for allowing us to study patients admitted under their care. The laboratory in which the estimations were made was supported by the Medical Research Council.

Requests for reprints should be addressed to Dr. T. C. Northfield, Guy's Hospital, London S.E.1.

\section{References}

Boehringer, C. F., und Soehne (1967). Lactate and Pyruvate Determination by UV Method; Biochemica Test Combination, 4th edn. Ingelheim am Rheim.

Boyan, C. P., and Howland, W. S. (1963). Fournal of the American Medical Association, 183, 58 .

Cannon, W. B. (1918). Fournal of the American Medical Association, 70, 531.

Cournand, A., et al. (1943). Surgery, 13, 964 .
Davidson, C. S., Lewis, J. H., Tagnon, H. J., Adams, M. A., and Taylor, F. H. L. (1946). New England fournal of Medicine, 234, 279.

Deller, F. C. (1948). The Modern Management of Gastric and Duodenal Ulcer, p. 66. Edinburgh, Livingstone.

Gain, E. A. (1962). Canadian Anaesthetists' Society fournal, 29, 207

Gain, E. A. (1962). Canadian Anaesthetists' Society fournal, 29, 207. Halmagyi, D. F. J., Gillett, D. J., and Irving, M. H. (1967). Fournal of Applied Physiology, 22, 487.

Howland, W. S., Boyan, C. P., and Schweizer, D. (1956). American fournal of Surgery, 92, 356.

Howland, W. S., and Schweizer, O. (1965). Clinical Anaesthesia, ed. L. R. Orkin, p. 26. Oxford, Blackwell Scientific.

Huckabee, W. E. (1958). Fournal of Clinical Investigation, 37, 244

Huckabee, W. E. (1961). American fournal of Medicine, 30, 833

Le Veen, H. H., et al. (1960). Fournal of the American Medical Association, 173,770 .

Nahas, G. G. Manger, W. M., Mittelman, A., and Ultmann, J. E. (1961). Annals of the New York Academy of Sciences, 92, 596.

Peretz, D. I., McGregor, M., and Dossetor, J. B. (1964). Canadian Medical Association fournal, 90,673 .

Root, W. S., et al. (1947). American fournal of Physiology, 149, 52. Siggaard-Andersen, O. (1963). Scandinavian fournal of Clinical Laboratory
Investigation, 15, 211 .

Takano, N. (1968). Respiration Physiology, 4, 32.

\title{
Gas Exchange in Renal Failure
}

\author{
M. J. GOGGIN, A. M. JOEKES
}

\section{Dangers of Hyperkalaemia during Anaesthesia}

\section{British Medical fournal, 1971, 2, 244-247}

\section{Summary}

Failure to maintain compensatory hyperventilation during anaesthesia in patients with metabolic acidosis results in an increase in $\mathrm{PaCO}_{2}$, fall in blood $\mathrm{pH}$, and a possible rise in plasma potassium. This sequence of events may account for unexplained operative deaths in patients in renal failure.

\section{Institute of Urology, London W.C.2}

M. J. GOGGIN, M.B., M.R.C.P., Lecturer in Nephrology

A. M. JOEKES, M.A., F.R.C.P., Senior Lecturer and Consultant Physician, St. Peter's Group of Hospitals

\section{Introduction}

Renal failure is the commonest background for the presence of a metabolic acidosis. Anaesthesia in patients with metabolic acidosis has long been considered a serious risk, quite independent of the anaemia which is almost invariably present. Fatalities during anaesthesia have not been adequately explained. In some instances hyperkalaemia has been accepted as a cause for cardiac arrest. We have lost several patients undergoing quite minor surgery, such as replacement of an external arteriovenous shunt. In some instances an electrocardiogram immediately before anaesthesia showed no evidence of hyperkalaemia, though the plasma potassium was above the normal range.

All patients with severe renal failure are likely to have respiratory compensation for the metabolic acidosis, with the $\mathrm{PaCO}_{2}$ well below normal. Control of respiration during anaesthesia tends to be based on the known minute volume 
and tidal volume maintaining the $\mathrm{PaCO}_{2}$ at $40 \mathrm{~mm} \mathrm{Hg}$. In a prospective study of anaesthesia in patients with renal failure we postulated that the respiratory compensation of the conscious patient might be abolished, giving rise to a sudden increase in $\mathrm{PaCO}_{2}$, a consequent fall in arterial blood $\mathrm{pH}$, and a possible rise in plasma potassium.

\section{Methods}

Patients were selected with various degrees of renal failure, who were to undergo anaesthesia. Some patients had recently been treated by haemodialysis or peritoneal dialysis, and in these the arterial blood $\mathrm{pH}$ tended to be above or at the upper end of the normal range.

Standard premedication techniques have been used and patients have had anaesthesia induced with thiopentone and some had suxamethonium for intubation. Operations have included transplantation, nephrectomy, biopsy, insertion of nephrostomy, and retrograde pyelography. For short operations not requiring paralysis patients have breathed halothane, nitrous oxide, and oxygen spontaneously. Those who required ventilation had this performed with Cape-Wayne, Drager, and Blease Manley machines.

Blood gas determinations were done by one of us (M.J.G.). Radiometer equipment was used.* Samples were collected by arterial puncture, heparinized syringes being used. $\mathrm{PaO}_{\text {. }}$, $\mathrm{PaCO}_{2}$, and $\mathrm{pH}$ measurements were made within 10 minutes of collecting the sample. The remainder of this was centrifuged and the plasma separated for potassium determination.

The $\mathrm{PO}_{2}$ electrode (E 5046, Clark-type) was calibrated for zero with borax and sodium sulphite, while the upper reading was calibrated by using the contents of the water-bath at $37^{\circ} \mathrm{C}$. The $\mathrm{Po}$, of this solution was calculated from the barometric pressure after the water vapour pressure at that temperature had been subtracted. The results were reproducible up to $2 \mathrm{~mm} \mathrm{Hg}$ in most of the range studied.

For the $\mathrm{PCO}_{2}$ a Severinghaus-type electrode (E 5036) was used. High and low carbon dioxide and oxygen mixtures were used (about $8 \%$ and $4 \% \mathrm{CO}_{2}$ ). Results could be repeated to $0.5 \mathrm{~mm} \mathrm{Hg}$ in the range that was being used.

$\mathrm{pH}$ determinations were done with a glass (G 297) and a calomel ( $\mathrm{K}$ 497) reference electrode standardized with Radiometer high ( $\mathrm{pH}$ 7.383) and low ( $\mathrm{pH}$ 6.841) buffers. Results were repeatable to 0.005 of a pH unit. With all the above a gas monitor (PHA 927), a pH meter (PHM 27), a water thermostat (VTS 13), and a thermostatted cell were used.

Potassium was measured with a flame photometer and $0.3 \mathrm{mEq}$ of potassium was considered to be a significant change.

\section{Results}

Details of the patients in the study are given in Table I. The changes in blood gases, $\mathrm{pH}$, and plasma potassium before, during, and after anaesthesia are shown in Table II.

If the $\mathrm{PaCO}_{2}$ is taken as an indication of ventilation then in cases $1 \mathrm{a}, 4,5,6$, and 9 the compensation for metabolic acidosis present during spontaneous conscious breathing was to a greater or lesser extent abolished during anaesthesia. In cases $1 \mathrm{~b}, 1 \mathrm{c}$, and 2 spontaneous overbreathing probably reflects a persistent intracellular acidosis with excessive compensation for extracellular $\mathrm{pH}$; during anaesthesia the reduction in ventilation tends to correct the extracellular respiratory alkalosis. In case 7 the problem was complicated by hypoxia in the presence of a profound anaemia; nevertheless, there was also a pronounced increase in Paco, during anaesthesia. In general terms the $\mathrm{pH}$ shifted inversely with $\mathrm{PaCO}_{2}$ changes during anaesthesia.

- Supplied by V. A. Howe \& Co. Ltd., 46 Pembridge Road, London W.11.
TABLE 1-Clinical Details of Patients in the Study, Including Endogenous Creatinine Clearances

\begin{tabular}{|c|c|c|c|c|}
\hline $\begin{array}{l}\text { Case } \\
\text { No. }\end{array}$ & Age & Sex & $\begin{array}{l}\text { Creatinine } \\
\text { Clearance } \\
(\mathrm{ml} / \mathrm{min})\end{array}$ & Comment \\
\hline $1 \mathrm{a}$ & 66 & M. & $\mathbf{0}$ & Carcinomatous obstructive uropathy. \\
\hline $\begin{array}{l}1 \mathrm{~b} \\
1 \mathrm{c}\end{array}$ & 57 & M. & $\begin{array}{r}42 \\
40 \\
0\end{array}$ & $\begin{array}{l}\text { Nephrostomy inserted } \\
\text { Second nephrostomy } \\
\text { Biopsy of pelvic mass } \\
\text { End-stage renal disease. Retrograde }\end{array}$ \\
\hline $\begin{array}{l}3 \\
4\end{array}$ & $\begin{array}{l}51 \\
39\end{array}$ & $\begin{array}{l}\text { M. } \\
\text { M. }\end{array}$ & $\begin{array}{l}\mathbf{0} \\
\mathbf{0}\end{array}$ & $\begin{array}{l}\text { pyelograms } \\
\text { End-stage renal disease. Transplantation } \\
\text { Obstructive uropathy. Single kidney. }\end{array}$ \\
\hline 5 & 43 & M. & 0 & End-stage renal failure. Cystine stones. \\
\hline 6 & 63 & M. & 35 & $\begin{array}{l}\text { Retrograde pyelograms } \\
\text { Carcinomatous obstructive uropathy. }\end{array}$ \\
\hline $\begin{array}{l}7 \\
8\end{array}$ & $\begin{array}{l}23 \\
45\end{array}$ & $\begin{array}{l}\text { M. } \\
\text { M. }\end{array}$ & $\begin{array}{l}\mathbf{0} \\
\mathbf{0}\end{array}$ & $\begin{array}{l}\text { Biopsy } \\
\text { Renal infection. Transplant nephrectomy } \\
\text { Single dysplastic pelvic kidney. } \\
\text { Cystoscony }\end{array}$ \\
\hline 9 & 32 & M. & 6 & $\begin{array}{l}\text { Cystoscopy } \\
\text { Uric acid obstructive uropathy. } \\
\text { Retrograde pyelograms }\end{array}$ \\
\hline 10 & 31 & M. & 0 & Glomerulonephritis. Nephrectomy \\
\hline
\end{tabular}

In Fig. 1 the changes in plasma potassium and $\mathrm{PaCO}_{2}$ during anaesthesia and conscious breathing are plotted and show a striking positive correlation (correlation coefficient 0.693). In cases la and 2 (Fig. 2) the plasma potassium changes with alterations in acid base balance are plotted on a Davenport diagram.

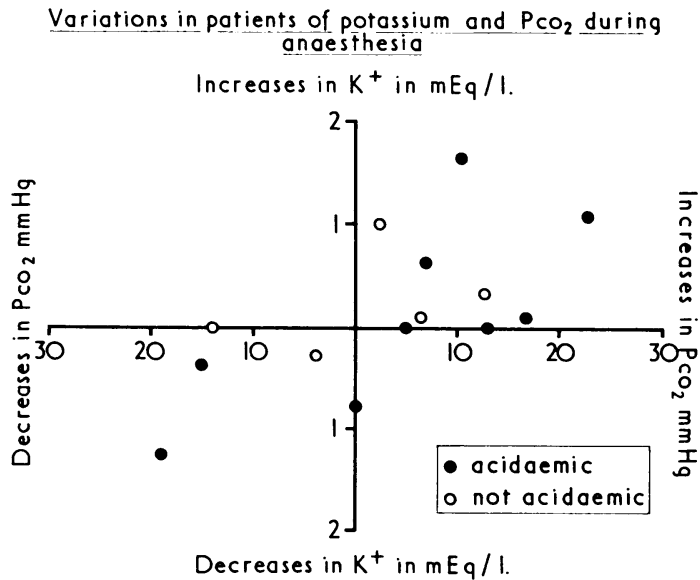

FIG. 1-Changes in plasma potassium which occurred in rclation to changes in the $\mathrm{PCO}_{2}$ before, during, and after anaesthesia.

In case 6 the period of anaesthesia was only 15 minutes and in all other cases the patients had been anaesthetized for at least 30 minutes before arterial samples were collected.

In cases 3 and 8 very small or no changes in $\mathrm{PaCO}_{2}$ occurred. Large increases in the $\mathrm{PaO}_{2}$ and the potassium rose in Case 3 and fell in Case 8.

In Case 10 the possible danger of hyperkalaemia due to underventilation had been appreciated. Though a preceding haemodialysis had induced a mild alkalosis moderate overventilation during anaesthesia prevented any change in plasma potassium.

\section{Discussion}

The present work supports the postulate that the failure to maintain compensatory overbreathing during anaesthesia in patients with renal failure could explain fatalities due to a sudden rise in plasma potassium.

Cardiac conduction disturbances during anaesthesia in uraemic patients have been studied by Compamanes et al. (1959). Of 68 patients, 13 had a tachycardia, three a bradycardia, five various arhythmias, and three cardiac arrests. Of these 24 
TABLE II-Comparison of $\mathrm{PaCO}_{2}, \mathrm{PaO}_{2}, \mathrm{pH}$, and Plasma Potassium in Patients before, during, and after Anaesthesia. Details of Ventilation are Given and where Suxamethonium has been used is Indicated

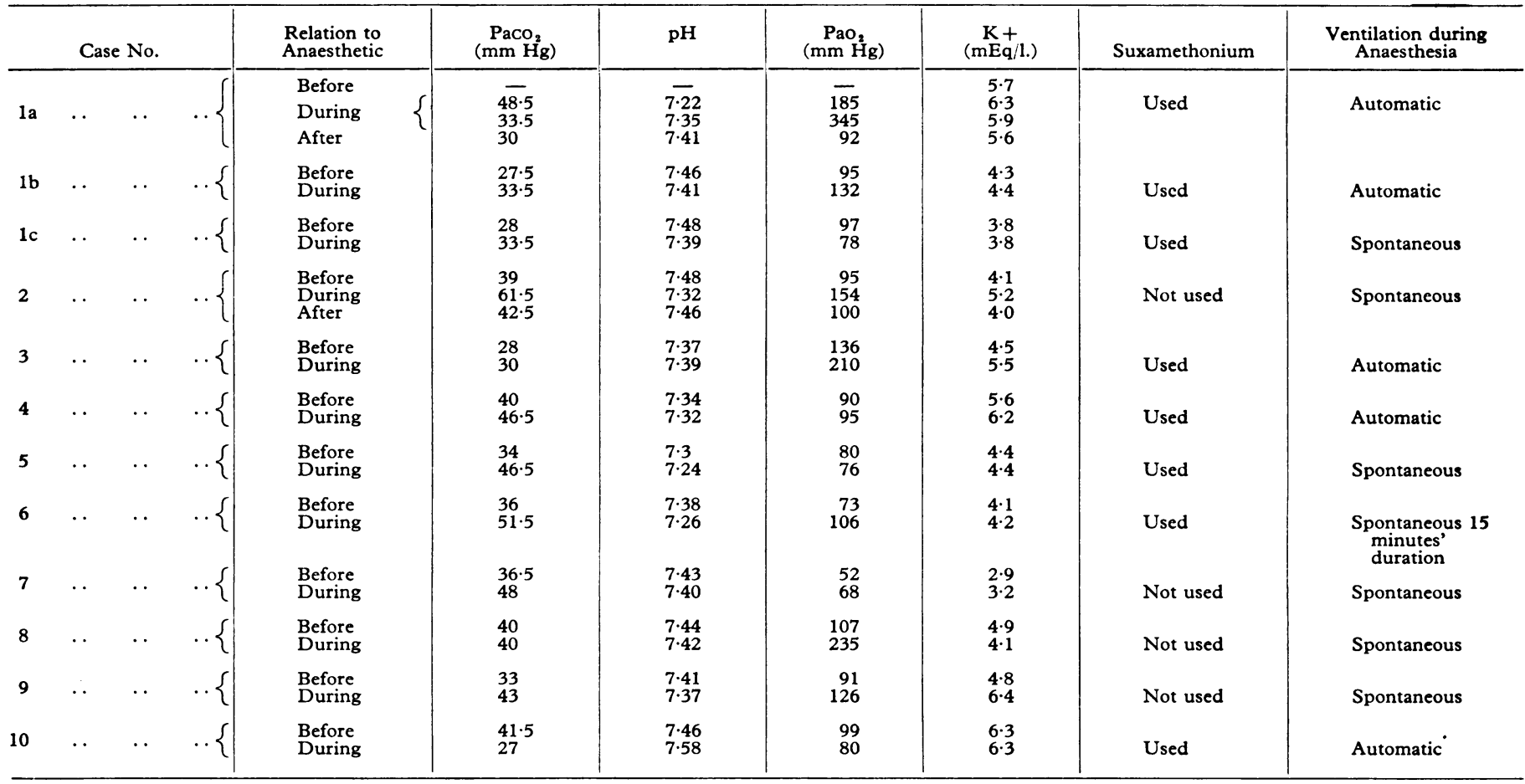

patients with renal failure, who had some cardiac rhythm abnormality during anaesthesia, 15 had raised serum potassium.

Goott et al. (1960), using healthy mongrel dogs, found that

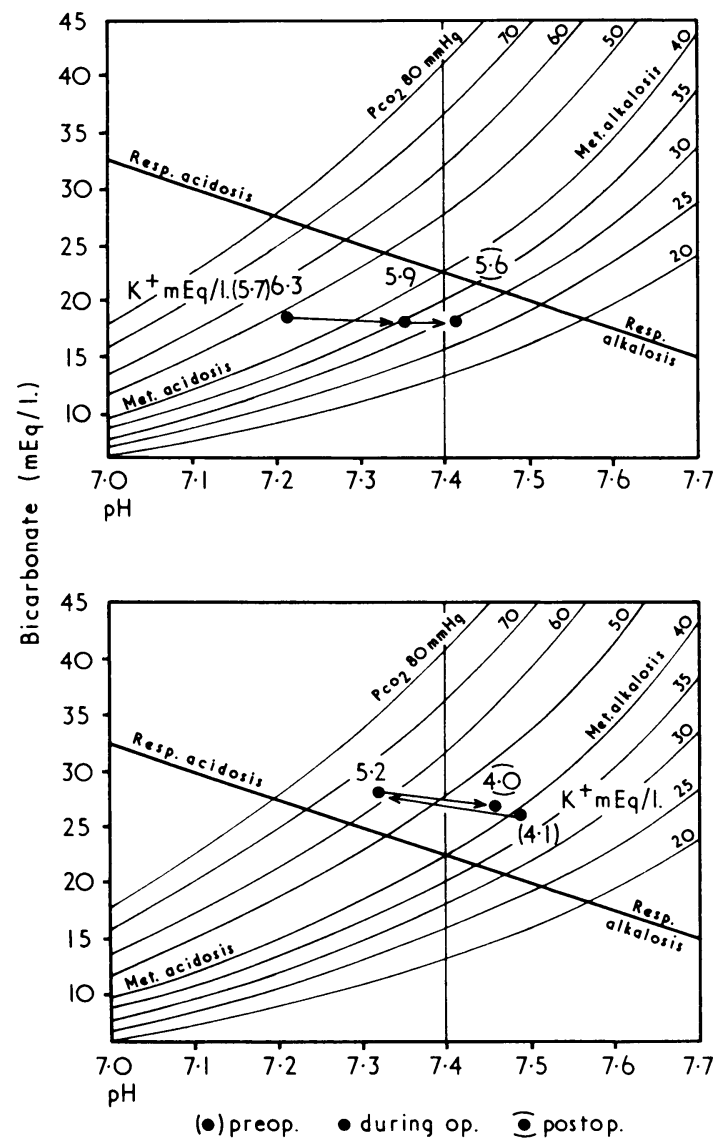

FIG. 2-Acid/base points are depicted on a Davenport diagram with values for the plasma potassium before, during, and after anaesthesia in Cases la (above) and 2 (below). there was a rise in arterial and coronary sinus blood potassium levels during respiratory acidosis. If the degree of hypercapnia was maintained during anaesthesia there was no further rise in plasma potassium, but there was a sudden rise in coronary sinus blood potassium immediately on stopping the hypercapnia and during this time severe cardiac arhythmias occurred.

The use of suxamethonium during anaesthesia has been incriminated as the cause of cardiac arhythmias due to a rise in plasma potassium. Paton (1956) showed that as much as $1 \%$ of muscle potassium could be released after the administration of suxamethonium to the isolated gastrocnemius muscle. It was also shown that the plasma potassium could be raised with suxamethonium in the intact animal and was thought to be due neither to sympathetic ganglion stimulation nor to the effect of sympathomimetic agents on the liver. Holmes et al. (1958) showed that haemodialysis with Kolff twin-coil kidney reduced the level of plasma cholinesterases, and Le Vine and Virtue (1964) emphasized that the use of suxamethonium in patients with renal failure treated by haemodialysis should be avoided. Katz et al. (1967) reported no adverse reactions during their routine use during 24 renal transplantation operations, but Löfström (1967) described three episodes of ventricular tachycardia and fibrillation in his series of 21 patients. Roth and Wütrich (1969) reported five cases of cardiac arrest after suxamethonium, two of these patients were uraemic with plasma potassiums exceeding $6 \mathrm{mEq} / 1$ before anaesthesia. Powell (1970) described the occurrence of hyperkalaemia and E.C.G. changes in the $T$ wave and loss of the $P$ wave with short runs of ventricular tachycardia in a uraemic patient after the use of suxamethonium in anaesthesia. The preoperative plasma potassium was normal and rose to $6.9 \mathrm{mEq} / 1$. during the operation. No blood gas studies were performed on this patient.

Of the 12 anaesthetics studied, suxamethonium was used in eight and not used in four cases. In the eight cases in which suxamethonium was used there was no significant rise in the plasma potassium during anaesthesia in five. In three of the four cases in which suxamethonium was not used there was a significant rise of plasma potassium; in one other 
patient (case 8) there was a significant fall of plasma potassium during the anaesthesia, but he was on oral potassium-absorbing resin.

The observations in the present work suggest that plasma potassium increases during anaesthesia in the presence of metabolic acidosis due to renal failure may be explicable on a rise in $\mathrm{PaCO}_{2}$ and a consequent fall in blood $\mathrm{pH}$. Our results do not support the suggestion that suxamethonium is an important factor, and previous publications ascribing such a hyperkalaemia to the effect of suxamethonium have failed to present any evidence on gas exchange.

In the presence of metabolic acidosis of renal failure safe anaesthesia must take into account the compensatory overventilation which is present in these patients. The characteristic findings on gas analysis are lowered $\mathrm{PACO}_{2}$ and a high or higher level than normal $\mathrm{PaO}_{2}$. The high oxygen partial pressure can be explained on the basis of a raised PAO: (alveolar oxygen tension) as a consequence of the lowered PAco: (alveolar CO. tension) because of the compensatory overventilation. Ideally, blood gases should be measured shortly before a patient with renal metabolic acidosis has to undergo anaesthesia, so that the ventilation during anaes- thesia will maintain the $\mathrm{PaCO}_{2}$ unchanged during anaesthesia. Frequently blood gas analysis is not practicable, but fortunately in the metabolic acidosis of renal failure there is a close correlation in the absence of pulmonary morbidity between the arterial carbon dioxide tension and the plasma bicarbonate as measured in the laboratory.

It must be emphasized that halothane anaesthesia with spontaneous breathing can also lead to hypoventilation in the context of a metabolic acidosis.

\section{Results}

Arterial blood gases were measured at the beginning and end of 12 peritoneal dialysis cycles; in seven before and after running in the dialysate and in five with the dialysate run in and after emptying. In Table IV the direction of change and absolute values are given, as well as the volume of the dialysis cycle. The values for $\mathrm{PaO}_{2}$ and $\mathrm{PaCO}_{2}$ and for the calculated $\mathrm{PAO}_{2}$ are also given. It is clear that $\mathrm{PaO}_{2}$ is reduced when the abdominal cavity is filled with dialysate. In most but not all cases the $\mathrm{PaCO}_{2}$ moves in the opposite direction to the $\mathrm{PaO}_{2}$. The calculated alveolar $\mathrm{Po}_{2}\left(\mathrm{PAO}_{2}\right)$, however,

\section{Pulmonary Gas Exchange during Peritoneal Dialysis}

\section{Summary}

Blood gas analysis studies have been made in patients undergoing peritoneal dialysis. It has been shown that oxygen tensions are reduced when fluid has been run into the peritoneal cavity and that this fall in $\mathrm{PaO}_{2}$ is reversed after running out the dialysate. The change in $\mathrm{PaO}_{2}$ is greater with 2-litre than with 1-litre cycles.

\section{Introduction}

Infective pulmonary complications of peritoneal dialysis were well described by Berlyne et al. (1966). He concluded that it was preferable to carry out peritoneal dialysis with 1-litre rather than 2-litre cycles to lessen the pulmonary complications. More recently Finn and Jowett (1970) described a case of acute hydrothorax complicating peritoneal dialysis.

The present observations have been made during different phases of peritoneal dialysis in patients who had no clinical evidence of pulmonary disease, in order to assess the effect on ventilation of introducing or removing fluid from the peritoneum.

\section{Methods}

Blood gas changes across 12 phases of peritoneal dialysis were studied in seven patients whose clinical details are given in Table III. Arterial blood samples were collected into heparinized syringes and $\mathrm{PaO}_{2}, \mathrm{PaCO}_{2}$, and $\mathrm{pH}$ were measured as soon as they reached the laboratory. Radiometer equipment was used and all blood estimations were carried out by one of us (M.J.G.). Details of the method are given in Part I.

Samples of blood were taken fairly near the start of dialysis, once it was established that the dialysis was proceeding satisfactorily. The sample was taken when the fluid had been run in or run out. In order that the change in blood gases could be measured, if the first sample was taken during the full phase another was taken as soon as that fluid had been run out or vice versa.
TABLE III-Clinical Details of Patients who had Blood Gas Studies during TABLE III-Clinical Details of Patients who had Blood Gas Studies during
Peritoneal Dialysis. Creatinine Clearance was less than $5 \mathrm{ml} / \mathrm{min}$ in All Cases

\begin{tabular}{c|c|l}
\hline $\begin{array}{c}\text { Patient's } \\
\text { No. }\end{array}$ & $\begin{array}{c}\text { Exchanges Listed } \\
\text { in Table II }\end{array}$ & \multicolumn{1}{|c}{ Diagnosis } \\
\hline 1 & 1 & Polycystic renal disease \\
2 & 3 & Cystinuria. End-stage renal failure \\
3 & 7 & Congenital abnormalities with end-stage renal failure. \\
4 & 6 & Glomerulonephritis \\
5 & 2 & Obstructed single kidney \\
6 & 5 & End-stage renal disease \\
7 & $8,9,11,12,13,14$ & Glomerulonephritis \\
\hline
\end{tabular}

The patients were all male, undergoing peritoneal dialysis during the assessment period of their end-stage renal disease. All the patients had endogenous creatinine clearance of less than $5 \mathrm{ml} / \mathrm{min}$.

Values for the alveolar oxygen tensions were calculated according to the method suggested by Benzinger (1937). $\mathrm{PAO}_{2}$ (partial pressure of alveolar $\mathrm{O}_{2}$ ) $=\mathrm{PIO}_{2}$ (partial pressure of inspired $\mathrm{O}_{2}$ ) $-\mathrm{PaCO}_{2}$ (partial pressure of arterial $\mathrm{CO}_{2}$ ). To make this less approximate, allowing for the difference in the volumes of inspired and expired gases, $\mathbf{P A O}_{2}=$ $\mathrm{PIO}_{2}-\mathrm{PaCO}_{2} / \mathrm{RQ}$, where RQ (respiratory quotent) $=0.8$.

TABLE IV-Direction and Absolute Values of Changes in $\mathrm{PaO}$ ), $\mathrm{PaCO}_{2}$ ), and $\mathrm{PAO}_{2}$ ) in Relation to the Volume of Cycle during Peritoneal Dialysis, in Patients whose Details are given in Table I

\begin{tabular}{|c|c|c|c|c|c|c|c|}
\hline \multirow{2}{*}{ Exchanges } & \multicolumn{3}{|c|}{ Direction of Change } & \multicolumn{3}{|c|}{ Changes in $\mathrm{mm} \mathrm{Hg}$} & \multirow{2}{*}{$\begin{array}{c}\text { Cycle } \\
\text { Change } \\
\text { in Litres }\end{array}$} \\
\hline & $\mathrm{PaO}_{2}$ & $\mathrm{PaCO}_{2}$ & $\mathrm{PAO}_{2}$ & $\mathrm{PaO}_{2}$ & $\mathrm{PaCO}_{2}$ & $\mathrm{PAO}_{2}$ & \\
\hline $\begin{array}{r}1 \\
3 \\
7 \\
9 \\
14 \\
12 \\
6 \\
2 \\
8 \\
11 \\
13 \\
5\end{array}$ & $\begin{array}{l}- \\
= \\
= \\
= \\
= \\
\overline{+} \\
+ \\
+ \\
+ \\
+ \\
+\end{array}$ & $\begin{array}{l}\bar{t} \\
+ \\
+ \\
+ \\
+ \\
+ \\
+ \\
+ \\
+ \\
-\end{array}$ & $\begin{array}{l} \pm \\
+ \\
\pm \\
- \\
- \\
+ \\
+ \\
+ \\
+\end{array}$ & $\begin{aligned} & 136 \rightarrow 132 \\
& 82 \rightarrow 77 \rightarrow 77 \\
& 111 \rightarrow 98 \\
& 137 \rightarrow 132 \\
& 121 \rightarrow 118 \\
& 122 \rightarrow 113 \\
& 112 \rightarrow 86 \\
& 85 \rightarrow 101 \\
& 105 \rightarrow 119 \\
& 112 \rightarrow 122 \\
& 113 \rightarrow 121 \\
& 73 \rightarrow 78.5\end{aligned}$ & $\begin{array}{l}15 \rightarrow 14 \cdot 5 \\
34 \cdot 5 \rightarrow 36 \cdot 5 \\
32 \rightarrow 29 \\
33 \cdot 5 \rightarrow 37 \cdot 5 \\
22 \rightarrow 22 \cdot 5 \\
24 \cdot 5 \rightarrow 25 \cdot 5 \\
28 \rightarrow 31 \\
36 \rightarrow 33 \\
36 \cdot 5 \rightarrow 35 \\
24 \rightarrow 24 \cdot 5 \\
25 \cdot 5 \rightarrow 22 \\
41 \rightarrow 38\end{array}$ & $\begin{array}{l}142 \rightarrow 142 \cdot 5 \\
115 \rightarrow 113 \cdot 5 \\
120 \cdot 5 \rightarrow 122 \cdot 5 \\
115 \cdot 5 \rightarrow 110 \cdot 5 \\
132 \cdot 5 \rightarrow 132 \\
129 \cdot 5 \rightarrow 128 \\
124 \rightarrow 120 \\
114 \rightarrow 117 \cdot 5 \\
112 \rightarrow 113 \cdot 5 \\
130 \rightarrow 129 \cdot 5 \\
128 \rightarrow 132 \cdot 5 \\
108 \rightarrow 112.5\end{array}$ & $\begin{array}{l}+1 \\
+1 \\
+1 \\
+1 \\
+1 \\
+2 \\
+2 \\
-2 \\
=2 \\
-2 \\
-2 \\
-1\end{array}$ \\
\hline
\end{tabular}


invariably moves in the opposite direction to the $\mathrm{PaCO}_{2}$ This inverse relationship points to the possible importance of considering a fall in the $\mathrm{PaCO}_{2}$-very closely related to the alveolar $\mathrm{PCO}_{2}-$ causing a rise in $\mathrm{PAO}_{2}$ and $\mathrm{PaO}_{2}$, as may be seen in the hyperpnoea of renal failure acidosis.

\section{Discussion}

From the results presented it is clear that the abdominal filling with peritoneal dialysate interferes with pulmonary gas exchange. Two-litre cycles, not surprisingly, have a greater effect than a 1-litre cycle. The most important and often the only change is on the arterial $\mathrm{PaO}_{2}$. There was no known pulmonary disease in any of the patients studied, but in all cases there was a reduction of arterial $\mathrm{PaO}_{2}$ when the dialysate had been run into the abdomen, and equally there was an increase in $\mathrm{PaO}_{2}$ when the dialysate had been run out. The changes in $\mathrm{PaCO}_{2}$ were less consistent but in most cases moved in the opposite direction to that of $\mathrm{PaO}_{2}$. These findings would be consistant with some degree of basal pulmonary collapse during the presence of dialysate in the abdomen which was reversed when the abdomen was empty.

Berlyne (1966) ascribed the infective pulmonary complications of peritoneal dialysis to plugs of mucus being drawn down into the re-expanding pulmonary bases after temporary collapse during abdominal filling. In our own series infective pulmonary complications were not obvious but the rapid reversal of the arterial gas exchanges on emptying the abdomen cannot be accepted as an argument against Berlyne's hypothesis explaining the infective complications. Most patients with either acute or chronic renal failure are anaemic, and a reduction of arterial oxygen tension may be of considerable importance. With the evidence that the larger cycle tends to cause a greater reduction in $\mathrm{PaO}_{2}$ suggests that 1-litre cycles should be more frequently used, as was suggested by Berlyne for other reasons. Unlike the observations on anaesthesia in patients with metabolic acidosis due to renal failure peritoneal dialysis causes only minor changes in $\mathrm{PaCO}_{2}$ and it is unlikely that the metabolic acidosis is aggravated by this procedure, the more so as the dialysing fluid will contain acetate or lactate. Nor will the possibility of a sudden hyperkalaemia be of significance, as potassium is being removed during the dialysis.

We would like to thank Professor K. W. Donald, Dr. D. C. Flenley, and other members of the department of medicine, University of Edinburgh, for their helpful advice. Determinations of plasma potassium were performed by courtesy of Dr. G. A. Rose. Helpful co-operation from members of the department of anaesthetics of the Royal College of Surgeons made the first study possible. For charts and photographs we are indebted to the departments of medical illustration and photography of the Institute of Urology.

\section{References}

Benzinger, T. (1937). Ergebnisse der Physiologie, biologischen Chemie und experimentellen Pharmakologie, 40,

Berlyne, G. M., Lee, H. A., Ralston, A. J., and Woolcock, J. A. (1966) Lancet, $2,75$.

Compamanes, C. I., Boyan, C. P., Weldon Belleville, J., and Howland, W. S. (1959). Anaesthesia and Analgesia, 38, 283.

Finn, R., and Jowett, E. W. (1970). British Medical fournal, 2, 94. Goott, B., Rosenberg, J. C., Lillehei, R. C., and Miller, F. A. (1960).

Holmes, J. H horacic and Cardiovascular Surgery, 40, 625. (1958). Transactions of the American Society for Artificial Internal Organs, 44, 16.

Katz, J., Kountz, S. L., and Cohn, R. (1967). Anaesthesia and Analgesia Current Research, 46, 609.

Le Vine, D. S., and Virtue, R. W. (1964). Canadian Anaesthetists' Society fournal, 4, 425 .

Löfström, B. (1967). Scandinavian Fournal of Urology and Nephrology, 1,161

Paton, W. D. M. (1956). British fournal of Anaesthesia, 28, 470.

Powell, J. N. (1970). British fournal of Anaesthesia, 42, 806.

Roth, F., and Wütrich, H. (1969). British fournal of Anaesthesia, 41, 311.

\title{
Study of the Secular Trend in Asbestos Bodies in Lungs in London 1936-66
}

\author{
CHANG-HYUN UM
}

British Medical fournal, 1971, 2, 248-252

\section{Summary}

Thick sections $(30 \mu$ unstained) cut from blocks of lung tissue from 100 consecutive necropsies for the years 1936, 1946, 1956, and 1966 at the Archway Hospital, London, have been searched for asbestos bodies. The incidence rose progressively-0, 3, 14, and $20 \%$ respectively. The rise was not explained by the increasing age of death in the later years or by the likely effects of changes in the areas within London in which the deaths occurred. There was no simiiar increase in the incidence of other bodies in the lungs which might be mistaken for asbestos bodies. The rising incidence is shown to fit reasonably with a model based on the hypothesis that the risk of inhaling asbestos increases in relation to the cumu-

M.R.C. Pneumoconiosis Unit, Llandough Hospital, Penarth, Glamorgan CF6 1 XW

CHANG-HYUN UM, M.D., D.I.H., Member, Scientific Staff (Present address: c/o Department of Pathology, Brompton Hospital, London S.W.3) lative total of asbestos imported into the country from 1910 onwards. The rising incidence does not fit a model in which the risk depends simply on the current level of asbestos imports.

\section{Introduction}

Many recent studies have shown the high proportion of lungs in which asbestos bodies can be found (Thomson et al., 1963; Elmes et al., 1965; Meurman, 1966; Rotzsch, 1967; Ashcroft, 1968; Dicke and Naylor, 1969). Apart from Selikoff and Hammond (1970), no attempt has been made to see whether the proportion of lungs with such bodies has changed over the years as the amount of asbestos used has increased. Such a study might show whether there has been an increase in environmental pollution by asbestos fibres as detected by their retention in the lungs. An opportunity to make such a study was provided by the completeness of the pathological records at the Central Histological Laboratory of the Arch- 